\title{
Children's Perspectives on Scale Response Options of Subjective Well-Being Measures: A Comparison between Numerical and Verbal-Response Formats
}

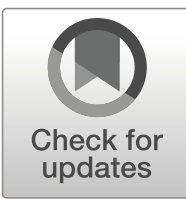

\author{
Carme Montserrat ${ }^{1}$ (D) Shazly Savahl ${ }^{2}$ (D) Sabirah Adams $^{3}$ (D) \\ Brîndușa Antonia Grigoraș ${ }^{4} \cdot$ Claudia Bacter $^{5}$ (D) Sergiu Bălțătescu $^{5}$ (iD
}

Accepted: 19 May 2020 / Published online: 28 May 2020

(C) Springer Nature B.V. 2020

\begin{abstract}
It is crucial to establish the validity of existing measures of children's subjective wellbeing (SWB) for use within specific contexts. Two important measurement issues that implicate the validly of SWB scales are 'question framing' and 'response options'. Fundamental to the latter is the concept of scale granularity, which refers to the number of response options imposed on a scale. However, the majority of studies on the topic have used adult and not child samples. The overarching aim of the study was to explore how children from three different contexts (Catalonia, Cape Town and North-Western Romania) perceive, understand, and make sense of SWB instruments, using focus group interviews and thematic analysis. A key finding of the study was the similarities in children's understandings of the response options across these contexts. While this does not represent a claim for a 'universal understanding' of measurement scale response formats, it is suggesting that there are similar cognitive processes that children across the contexts apply when making sense of and deciding on which response option to endorse (for both verbal and numerical formats). Another key finding is the unique perspective on the process of how children make sense of the scale declarative statement in relation to these response options, and the life aspects they draw on for the final endorsement. Future studies should endeavour to focus on a range of different contexts and cohorts of children and include various types of measurement scales and response options.
\end{abstract}

Keywords Scale granularity · Children's subjective well-being measures · Focus group interviews - Thematic analysis - Child participation

Carme Montserrat

carme.montserrat@udg.edu

Extended author information available on the last page of the article 


\section{Background}

\subsection{Introduction and Research Motivation}

Over the past few years there has been an increasing interest in research focused on children's subjective well-being (SWB). This was largely driven by the notion that objective measures only provide a partial explanation about child well-being, and what children think and feel about their lives and how they experience different aspects of their lives, are critical factors in understanding children's overall well-being (Ben-Arieh 2000; Casas et al. 2013; Savahl et al. 2015). Similarly, the 'new sociology of childhood' advanced the role of children as 'social actors' who actively participate in their family and society (see James and Prout 1990) and experts on their lives, who should be able to influence decisions about their lives and contribute to social change and cultural development (Corsaro 2008).

The development of novel quantitative and qualitative methodologies and research models to understand children's perceptions of their well-being has been foregrounded (Adams et al. 2017; Ben-Arieh et al. 2014; Rees and Dinisman 2015; Rees et al. 2016; Fattore et al. 2018). Noting the importance of obtaining children's subjective perceptions of well-being, it has become essential to engage with measures and instruments that can be used to collect data on children's subjective perceptions of well-being. A critical step in this process is to ascertain the state of existing measures and to verify their validity in the contexts they are intended to be used. Within the international literature, a number of instruments have been identified, which have shown good validity across a range of cultural contexts. Previously, the only psychometric scale assessing well-being was the single-item scale the 'Cantril Ladder' (Casas et al. 2013). More recent evidence suggests that the use of multi-item measures of SWB are more stable than single item measures (Casas et al. 2013), reduces the risk of measurement error, and increases the reliability of the measure. Multiple item measures include those that measure global life satisfaction (Students' Life Satisfaction Scale [SLSS]) and those measuring multiple dimensions (Personal Well-Being Index-School Children, [PWI-SC] the Multidimensional Students' Life Satisfaction Scale, [MSLSS] and the Brief Multidimensional Students' Life Satisfaction Scale [BMSLSS]). These measures have been tested and show good validity across a range of contexts (Casas and Bello 2012; Casas et al. 2013; González-Carrasco et al. 2019; Rees and Dinisman 2015; Savahl et al. 2019).

Nonetheless, a variety of measurement issues must be considered before these scales can be validly used. These issues can be classified into two categories, namely question framing and response options. Question framing concerns issues such as question length and order, grammar, specificity and simplicity, and response biases. Importantly, question framing also refers to the level of abstraction of the scale items. Response options involve a consideration of the response format, and the respondents' encoding of their responses. Fundamental to this latter category is the concept of scale granularity, which refers to the number of response options or cut-off points imposed on a scale (Smithson 2006).

\subsection{Response Options: Major Debates}

Central to the validity of any scale is its ability to capture the range of variation in the latent variable of interest in the sample. In theory, increasing the degree of granularity 
of scale items (i.e. increasing the number of response options) has the effect of increasing the sensitivity of the scale to variations in the underlying variable of interest, and therefore increases overall scale precision and discriminatory power. Supporting this assertion, a study by Pearse (2011) showed that high granularity scales can be useful (even up to 21-points), as evidenced by the wide spread of response options utilised by respondents in the study. Other research has also supported the usefulness of higher granularity items (though usually with fewer response options) (Lietz 2010). For example, Coelho and Esteves (2007) found superior discriminant validity for 10-point over five-point response options, while Saris et al.'s (2004) review of the then-current literature endorsed the superior validity and reliability of 11-point scales over lower granularity measures.

However, the relationship between scale granularity and item validity may not necessarily be a linear one, as demonstrated in a study by Preston and Colman (2000). They found that the optimal level of scale granularity increased from two points up to seven, and thereafter indices of optimal granularity (e.g. reliability, validity, discriminatory power) levelled off until 10-points. However, test-retest reliability decreased when more than ten response options were used. Preston and Colman (2000) recommend that careful consideration should be employed when deciding upon the level of scale granularity to use; which is advanced by the assertion of Pearse (2011), "that researchers should give more explicit attention to scale granularity when designing a questionnaire" (p. 159).

Despite the body of research supporting the use of higher granularity items, one noticeable shortcoming in the literature is the lack of research with child samples. This dearth is of particular relevance, owing to children's maturing cognitive development, and the potential this has to interact with scale granularity. In cases where children's levels of item comprehension are challenged, higher levels of scale granularity may exacerbate the burden already placed upon their cognitive abilities in completing items. Cook et al. (2001) echo this point, and caution against an indiscriminant preference for high granularity items without consideration of the participant's capacity to understand the meaning of the intervals. This is also relevant to child respondents, and may require the use of simpler (i.e. less granular) response options.

One of the reasons for the preference for relatively high granularity scales can be traced to the debate concerning the appropriateness of Likert-type scales for parametric analysis (Jones and Loe 2013). Strictly speaking, Likert-type scales produce only ordinal data, which is not suited for parametric analysis. However, in practice, most researchers consider Likert-type data to possess sufficiently equal distances between response options in order for parametric analysis to be used (i.e. Likert-type data is 'close enough' to interval data in order for parametric techniques to be used) (Jones and Loe 2013). Furthermore, a trend in academic thought in this regard has been to assume that higher granularity items provide a better approximation of interval level data, and are therefore preferable to lower granularity items (Jones and Loe 2013). Conversely, it is theoretically possible that by increasing the number of response options available, the construct in question becomes artificially dissected into more increments than it possesses, or at least more than respondents are capable of reliably differentiating (Jones and Loe 2013). In this sense, scale validity and precision would be reduced by increased granularity. 
Another issue pertinent to the debate around scale granularity is whether response options should be odd or even - i.e. whether or not a middle option, in which no directionality (i.e. no preference) is indicated, should be included (Lietz 2010). One of the arguments against inclusion of a mid-point option was initially made by Krosnick (1991), and is known as the 'satisficing hypothesis'. In essence, Krosnick (1991) hypothesised that owing to typically low levels of motivation on the part of survey respondents, they would naturally be inclined to select response options that require the least cognitive demand, and that this would produce a bias for 'middle' response options. O' Muircheartaigh et al. (2000) investigated these, and other issues around odd and even response options, and found that the exclusion of the middle response option resulted in lower validity, in opposition to Krosnick's (1991) 'satisficing hypothesis'. O' Muircheartaigh et al.'s (2000) findings are reiterated by a metaanalysis by Saris and Gallhofer (2007), in which the inclusion of a middle response option was found to enhance scale validity in the research under review.

In addition to the debates related to scale granularity discussed above, issues around the labelling of response options are noteworthy to consider, given the influence on scale responses. These issues include:

- whether or not to include negative items in numerical response scales (e.g. -5 to 5 , or 0 to 10 )

- whether to adopt verbal response options (e.g. Strongly disagree to Strongly agree),

- how to label the different response points (if at all).

In relation to the first point, there is a general consensus that bipolar numerical response options result in a higher incidence of positive responses (i.e. responses above 0), in comparison to unipolar response options (Lietz 2010). As such, unipolar response options provide a more even distribution of responses, which may be preferable. The question of whether to use verbal anchors can also be difficult, however, a study by O'Muircheartaigh et al. (1995) found that the inclusion of verbal anchors on a $0-10$ scale resulted in the ' 0 ' response being selected on occasion, whereas with a purely numerical response scale no such responses were observed. Schwarz et al. (1991) also investigated the interaction between the use of verbal anchor points in various response scales, and found that both the numerical and verbal cues are used by respondents in interpreting the meaning of scale points. In this regard, Saris and Gallhofer (2007, p. 244) note that a "Making the numbers correspond with the labels has a significant positive effect on reliability." As such, the use of verbal anchor points has been recommended, as they provide supplementary information to numerical scale points, which is used by respondents and increases overall scale precision. Lastly, the nature of the verbal labels utilised is also of relevance to scale validity, and is evident from the effect that different types of verbal anchors have on scale responses. More specifically, word choice as well as the use of adverbs in verbal anchors have been shown to have a significant effect on scale responses (Lietz 2010). A pertinent point in this regard is that of different understandings of verbal labels intended to reflect varying levels of intensity (e.g. 'fantastic' vs 'excellent', or adverbs such as 'very good' vs 'really good'). It should be noted that the respondents may understand the labels in ways other than intended by the researcher, thereby creating confusion and reducing scale validity. The choice of verbal anchors is therefore difficult, but underscores the 
importance of scales that are validated among the population they are intended to be used.

The above discussion provides an overview of the most salient issues related to scale granularity. However, the majority of studies have employed adult samples, which differ qualitatively from child samples. The most pertinent issue to consider in this regard is how scale granularity might affect child respondents differently from adults. Despite a general consensus in the literature that moderately high granularity scales are preferable (up until about 11 points, with some studies recommending fewer), due to the potential increase in precision and scale discriminatory power that higher granularity invokes, the case is not straightforward for child samples. Higher granularity items require that respondents possess the cognitive capacity to differentiate between the numerous response points in terms of the underlying construct of interest (Cook et al. 2001). In the case of children, their developing cognitive capacity (especially for younger children), may impact on such understandings to the extent that scale precision is reduced. A related concern is the assumption that children and adults experience the same construct in sufficiently similar ways for the same scale and response options to be equally valid for both groups. However, the fact that the majority of psychological constructs have been investigated using adult samples only, suggests that this assumption should be headed with caution. Finally, given that children may have difficulty in differentiating the construct of interest into numerous increments that higher granularity scales require, this may also reduce scale precision and validity (especially in the case of SWB, where the nature of the constructs involved are inherently subjective and difficult to empirically quantify). These impediments to the use of high granularity scales with children necessitates child-specific research in order to ensure that the scales used are capable of tapping the latent variables of interest in children, and thereby ensuring that the results are reflective of children's voices.

The current study intends to qualitatively investigate these issues, by exploring how child respondents understand the five-point versus the 11-point response options on the SLSS and the PWI-SC, in an effort to ascertain which of the response options are preferable.

\section{Aim of the Study}

The overarching aim of the study was to explore how children from three different contexts (Catalonia, Cape Town, and North-Western Romania) perceive, understand and make sense of SWB instruments. The following objectives were developed to guide the process:

- To explore children's understandings of, and decision-making process used when completing measurement instruments on SWB, specifically as it relates to numerical versus verbal response formats.

- To determine children's preferences for either numerical or verbal response formats.

- To understand how children make sense of, and understand, key concepts related to SWB. 


\section{Method}

Given the aims of the study, a qualitative methodological approach was followed.

\subsection{Description of Sample}

The study was conducted in three countries namely, Spain, South Africa, and Romania, which form part of the Children's Worlds project (www.isciweb.org), a worldwide research survey on children's SWB using a quantitative approach with a selfadministered questionnaire, since its inception in 2010. The differences among these countries in cultural, linguistic, and socio-economic terms could contribute to understandings of children's responses from different perspectives. This criterion was applicable to the selection of the country and the schools, not the individuals. The agreedupon inclusion criteria used by the country research teams to select children for the study were:

- The age group of 11 to 12 -year olds, corresponding to the 6th grade of primary school in all three contexts.

- A reasonable equal gender split across the sample.

- Those who indicated a willingness to participate in the study, with parental consent.

- Two groups per country with ten participants in each group.

A total of 58 children participated in the study using focus group interviews. The participants were selected by means of purposive sampling (see Table 1). Subsequent to participants agreeing to voluntarily participate in the study and providing parental consent, and taking into account the inclusion criteria, six groups of between eight to 10 children were conducted.

The South African sample consisted of two groups of children selected from lowermiddle socio-economic status schools in the Cape Town metropole. The participants were all English first-language speakers. Group One consisted of eight participants, four boys and four girls; while Group Two consisted of 10 participants comprising four boys and six girls.

The Romanian team included two sixth grade groups of 12-year olds. Both groups comprised 10 participants each, with the first group selected from a school in Cluj-

Table 1 Participants in each country

\begin{tabular}{llllll}
\hline Country & Technique & Girls & Boys & Age range & Total \\
\hline Romania & Focus group 1 & 5 & 5 & 12 & 10 \\
& Focus group 2 & 5 & 5 & 12 & 10 \\
Western Cape (South Africa) & Focus group 1 & 4 & 4 & $11-12$ & 8 \\
& Focus group 2 & 6 & 4 & $11-12$ & 10 \\
Catalonia (Spain) & Focus group 1 & 5 & 5 & $11-12$ & 10 \\
& Focus group 2 & 5 & 5 & $11-12$ & 10 \\
Total participants & 6 focus groups & 30 & 28 & $11-12$ years old & 58 \\
\hline
\end{tabular}


Napoca (a city located in North-Western Romania with about 320,000 inhabitants), and the second in the rural locality of Nojorid, also situated in the North-West of Romania. The gender distribution was even for both groups and the participants were Romanian first-language speakers.

The Spanish sample consisted of two groups of children selected from two middle socio-economic status schools (one state and the other state-subsidized) in two villages of the Girona province (located in the coast, with 20,000 and 10,000 inhabitants respectively). The participants were mainly Catalan first-language speakers and the groups were conducted in the Catalan language.

\subsection{Instrument and Data Collection Process}

The focus group interviews were conducted after the participants responded to a questionnaire with the rest of classmates in their classroom. Each focus group discussion was conducted after school hours on the school premises and was approximately one to one hour and twenty minutes in duration. The groups were facilitated by two researchers in each country, one moderator and a cofacilitator, with experience in conducting qualitative research with children. The following guidelines were employed by each research team in order to systematically and rigorously conduct the research:

- Consent for participation from the child participant as well as the child's parent/ guardian was obtained prior to the focus groups.

- The focus groups were conducted at the school, after the questionnaire administration (The 'questionnaire' refers to the Children's worlds questionnaire, see www. isciweb.org for further details)

- The participants are to be seen as experts on their lives, and the researchers sought their advice in this regard.

- To inform the participants about the research aims and establish rules at the beginning. This includes an explanation of the procedures, the role of the moderator and co-facilitator, and information about how the material provided and data will be used, including the ethics related to the study such as confidentiality and the consent about the recording of the interviews.

- To create a trusting atmosphere between the participants and the moderator, and build rapport. It was helpful to start with some warm-up questions, and icebreakers.

- Show the materials that will be provided for discussion.

- The duration of focus groups should be around an hour.

- Participants should also be allowed to leave the focus group before it ends, as participation is voluntary.

- A small gift could be offered at the end of data collection, for example pens with the name of the university.

The following study objective was objective of the study was explained to the participants: After answering the questionnaire, we need your help to improve our understanding of your point of view. When we ask children of your age group living in different countries about how they feel about their lives in general, and whether they 
feel their lives are good, we are not sure if we correctly/accurately understand the meaning of their responses and how to ask the questions. We need your advice. Maybe you can provide us with an explanation to improve the questions used here. Can you please help us? To discuss these issues, we have a few cards with some examples.

After this explanation, the moderator used the following interview schedule, which are aligned to the objectives of the study, to commence the discussion. Here are some examples of questions used:

a) Imagine that you are in front of a question like this in the card (a big card, which the participants can touch) with eleven possible options from 0 (Not at all satisfied) to 10 (Totally satisfied). If you tick the box xx, what does it mean to you? Or another question could be for example: If you are 'quite satisfied', which number would you choose? What is the meaning of each number to you?

b) When you have to answer a question like this in the card (also a big one) with five options about agreement, if you tick the box 'agree somewhat', what is the meaning for you? Or When do you choose 'Don't know'?

c) What is the meaning of the word satisfaction to you? What are the words used for you with the same meaning? Is there a difference between being satisfied and happy to you?

d) What kind of questionnaire do you prefer - with labels or numbers? What are the differences between them? On line or in a paper form? If you have to study the satisfaction with life among children at your same age, how would you do this?

\subsection{Ethics}

The standard ethics principles associated with research with children was applied by each country research team. Permission to conduct the study was obtained by each respective institution, and relevant education authorities in each country. Each participant was requested to provide signed consent as well as to obtain signed consent from their parent/s or guardian/s. Participants were advised and assured of their confidentiality and a clear indication was provided in relation to access and future use of the data.

\subsection{Data Analysis}

The data for the study were analysed using thematic analysis. Once the transcripts were verified in each language, the Romanian and Catalan groups were translated to English, and the data were coded into themes, following guidelines by Braun and Clarke (2006). The researchers read the transcripts several times in order to prepare the data for the identification of emerging codes (for example, 'M10' as the meaning of value 10), themes (for example, '10 as totally satisfied'), and categories (for example 'Meaning assigned to numerical values in an eleven-point scale'). This process entailed scrutinising the transcripts for similarities and themes that informed the creation of codes, themes, and thematic categories followed by a rigorous reflection, synthesis, and transformation of the central themes. In the final step the emerging themes were transformed from each cluster of raw data into final thematic categories. This is expounded on in the Results section below. 


\section{Results}

The four thematic categories that emerged were:

- Meaning assigned to numerical values in an eleven-point scale (0-10)

- Meaning assigned to response options in a five-point Agree/Disagree scale

- Analysis of the meaning of some concepts used in the questionnaire, and

- Preferences of question and instrument types

The results are presented in line with the objectives of the study, and illustrated by tables with the categories and subcategories that emerged in each theme, taking into account the consistency and intensity of the comments. The frequency of the responses in each group has not been included in the tables. In this section the actual choice and meaning of the words used by the participants are presented.

\subsection{Meaning Assigned to Numerical Values in an Eleven-Point Scale (0-10)}

Table 2 provides a generalised account of how children assign meaning to the various numerical scale response options.

\subsubsection{Values 10,9 , and 8}

For option "10", the participants in the three countries were unanimous in relation to the meaning. They were in agreement that the " 10 " option represented a sense of being completely satisfied and happy with their lives.

Interestingly in Cape Town, they intonated the numerical '100\%' to emphasise their position and to qualify their narrative. Another interesting point to note is the emphasis that the participants placed on the option being chosen "only when all things in your life are going well" and the perception that there is no problem in any part of their lives. In

Table 2 Meaning of values in an 0-10 scale according to the children

\begin{tabular}{llll}
\hline Category: Meaning assigned to numerical values & \multicolumn{2}{l}{ Was this topic discussed in each group? } \\
\cline { 2 - 4 } Sub-categories: & South Africa & Spain & Romania \\
\hline 10= Totally satisfied & Yes & Yes & Yes \\
$9=$ Extremely satisfied, but there could be a problem & Yes & Yes & Yes \\
$8=$ Satisfied, but there are something bothering them & Yes & & \\
$7=$ More positive than negative & & Yes & Yes \\
$7=$ Mid-point & Yes & Yes & \\
$5-6=$ Below the average, more negative than positive & Yes & Yes & \\
$5=$ Mid-point & & & Yes \\
$3-4=$ Important problems exist & Yes & Yes & Yes \\
1-2= Struggling at all levels & Yes & Yes & \\
$0=$ Everything in your life is going very bad & Yes & Yes & \\
\hline
\end{tabular}


Catalonia, they used expressions like "Totally happy", "You have a lot of friends", and a "Feeling of freedom". In North-Western Romania, children recognise that most of them tick the box with the number 10 qualified with expressions like "excellent" and "very happy".

For the scale response option "9", participants in the three countries indicated that it meant being extremely happy, and that it was very similar to choosing a "10" except that it could be that a minor problem was being experienced. In Cape Town, when probed to elaborate, the participants indicated that it could be a minor schoolrelated problem, a minor altercation with a friend, or something within the family. In Catalonia, although they also regarded "9" as a high score, a quarter of the participants stated that it indicated the existence of a problem like "It means that you have a worry", "You are not completely free". In NorthWestern Romania, "9" also meant a high score and they used expressions like "fairly satisfied", "but would like to have more space for playing", "would like to change something", or being "Close to total".

In Cape Town, a similar explanation was provided for response option " 8 ". Here the participants explained that this option would be chosen if there is a minor problem in either one of the home or school setting; but qualified the response by stating that it would not be a "big problem".

\subsubsection{Value 7 and 6}

Response option "7" had different meanings across the groups. In Cape Town and Catalonia, for most children the option "7" was classified as the "normal" or average response. They directly used terms as "average" or "mid-point". The participants said that this option indicated a reasonable state of satisfaction and that only normal day-today problems were being experienced. Interestingly, the participants believed this to be the default or baseline choice for children when considering the various scale responses. In this way, they evaluate their lives against this baseline. The assessment considers both the presence of positive factors and the absence of negative factors. The narratives in Cape Town were "Means that you are just normal", "You kind of satisfied or okay with your life". "You only have normal day to day problems that children have". In Catalonia they also situated " 7 " as the mid-point on the 0-10 scale, using expressions like "It is a mid-point", "Not a lot satisfied but a little", and "50-50", "This is because 5 and lower than 5 would be a fail, as a metaphor...". In this case they were comparing it to the system of marks at school. Others went even further, claiming that this score meant a "lack of happiness", "You have some problems", "You do not have enough friends". Another example of the mid-point meaning of score option "7" was demonstrated by participants in the Cape Town groups, who unanimously felt that response option "6" indicated that the level of life satisfaction was "below-average". They used the response option " 7 " as a starting point to explain the choice and meaning of " 6 ", by stating that this option would likely be chosen if there were a few things that were causing distress in their lives and if it resulted in slight feelings of distress thus, "you are okay, but there are a few problems that's affecting your life".

However, in Romania, although there was an example that supported this, namely: "Quite satisfied, but some things you don't have: a bed, a comfortable bed, more space for you and your family"; on the other hand, most of the participants thought that the meaning was more positive than negative with expressions like: "More towards 
satisfied", "More towards totally satisfied", "Almost very happy", and they did not situate " 7 " as a mid-point. This was echoed by a participant in Catalonia who expressed that this response option meant "More freedom than lack of it".

\subsubsection{Value 5}

On an 11-point, that is a $0-10$ scale, 5 is usually regarded as the mid-point between high and low options. However, most of the participants in Cape town and Catalonia felt that response option " 5 " would be selected if there was an unequal ratio of negative to positive factors being experienced. The participants stressed that this meant that the respondent was experiencing difficulty across a number of contexts. The narratives from the participants in Cape Town to support this were "We mean you have way more negative things actually", and "You will probably be quite stressed". Similarly, examples from Catalonia were: "You are not happy", "He or she has a big problem", "When your parents neglect you", and "Five is really low". On the other hand, children from North-Western Romania situated the score 5 as a mid-point saying: "Neither satisfied nor dissatisfied", "Middle satisfied", "A little better, satisfied, but some things must be added", with a quarter of participants in Catalonia indicating that: "Like hot water and cold water", "50-50".

\subsubsection{Values 4 and Below}

In all the groups children stated that a score of " 4 " and below meant that significant problems were experienced in their lives. For example, in Cape Town children indicated that response options " $3-4$ " would be selected if there were a significant amount of negative experiences across the home and school contexts or with a range of significant people: "You have lots of problems; probably problems at home or school"; "Maybe you could have problems with your friends at school; or feel left out at school"; "perhaps you could be bullied at school"; and "Or maybe you have problems at home e.g. your parents are fighting". In Catalonia most children stated similarities with the academic rating marks system like: "Four is like failing but not with the lowest marks!", "Three means that you are on the edge...", "Three would be same as 0, wouldn't it?", "Three is failing", and also: "Three would means you are so dissatisfied that you would blame yourself!". In North-Western Romania, a score of "4" indicated that important problems exist, and the examples presented by children focused on general aspects of their lives and in housing; "Almost totally dissatisfied", "you would like to change quite a lot", "Start to not like: mould in the house, insufficient number of rooms and space", and "the house is not comfortable and decorated enough".

In Cape Town the selection of response options " $1-2$ " indicated major problems with your life. The participants felt that the selection of "1-2" meant that the respondents were "hanging on by a thread"; metaphorically implying a critical moment in the lives of children.

\subsubsection{Value 0}

Finally, the participants felt that the selection of response option " 0 " meant that "everything is going very bad". The participants indicated that the selection of 
this option meant that the child was experiencing extreme negative experiences across all aspects of their lives. They specifically pointed to the likelihood of feelings of marginalisation and loneliness with the following narratives expressed in Cape Town: "If you choose a zero, then you are in big trouble", "You feel alone in this world", "you feel that no-one cares about you", "you cannot see a way out of your troubles". They also referred to severe problems at school like: "You probably doing very poorly at school"; "you probably have no friends, or you are being left out or being bullied", and within the family: "you probably have major problems in your family", "You will only choose zero if things at home and school and with your friends are going terrible." Interestingly, with these narratives they intonated the core issues in terms of child well-being. In Catalonia, the participants said similar things, such as "If they would choose a 0 is because they are being bullied or they have no friends", "They are not good students, they have bad marks and the teacher is not supporting them", "Maybe their parents are fighting", "Maybe they are making an effort to have good marks but nobody trusts them". However, it is interesting to underline that in one of the groups in Catalonia almost half of participants considered that $0-5$ was rarely used in their responses when answering the survey as none of them were dissatisfied.

\subsection{Meaning Assigned to Response Options in a Five-Point Unipolar Agreement Scale}

In Table 3 the meanings assigned to response options on a five-point labelled scale are presented.

Table 3 Meaning of response option values in a five-point unipolar agreement scale

\begin{tabular}{|c|c|c|c|c|}
\hline \multicolumn{2}{|c|}{ Category: Meaning assigned to categorical values } & \multicolumn{3}{|c|}{$\begin{array}{l}\text { Was this topic discussed in each } \\
\text { group? }\end{array}$} \\
\hline Sub-categories: & & $\begin{array}{l}\text { South } \\
\text { Africa }\end{array}$ & Spain & Romania \\
\hline $\begin{array}{l}\text { Meaning of Do } \\
\text { not agree (1) }\end{array}$ & $\begin{array}{l}\text { Equivalent on the } 0-10 \text { scale would be values } 0-2 \\
\text { Unlikely to be selected }\end{array}$ & $\begin{array}{l}\text { Yes } \\
\text { Yes }\end{array}$ & Yes & Yes \\
\hline Agree a little (2) & Equivalent on the $0-10$ scale would be values $3-4$ & Yes & Yes & Yes \\
\hline Somewhat Agree (3) & $\begin{array}{l}\text { Average score } \\
\text { Equivalent on the } 0-10 \text { scale would be values 5-6 } \\
\text { Other values (higher or lower) }\end{array}$ & $\begin{array}{l}\text { Yes } \\
\text { Yes }\end{array}$ & $\begin{array}{l}\text { Yes } \\
\text { values } 5-7 \\
\text { Yes }\end{array}$ & $\begin{array}{l}\text { Yes } \\
\text { values } 5-7\end{array}$ \\
\hline Agree (4) & Equivalent on the $0-10$ scale would be values $7-8$ & Yes & values 6-9 & Yes \\
\hline Strongly Agree (5) & Equivalent on the $0-10$ scale would be values $9-10$ & Yes & Yes & Yes \\
\hline Don't know & $\begin{array}{l}\text { - not sure about the question } \\
\text { - don't know the answer } \\
\text { - don't understand the question }\end{array}$ & Yes & Yes & Yes \\
\hline & Don't want to show your opinion/feeling & & Yes & \\
\hline
\end{tabular}




\subsubsection{Do Not Agree}

The participants indicated that the response option "Do not agree" would be chosen if the participants identified with a definite sense of disagreement. They explained that they understood the option in its literal sense. Given that the question related to the 'amount of friends', the participants indicated that this simply meant that they felt that they do not have enough friends in Cape Town, a "lack of friends" or "difficulty in making friends" in Catalonia, or "You feel alone, you need more friends that you like" in North-Western Romania. They indicated that the equivalent value on a numerical scale would be between 0 and 2. The participants in Cape Town further indicated that this option was unlikely to be selected given that most children would have friends; unless they were feeling marginalised. The same was found in Catalonia regarding the lower numerical values.

\subsubsection{Agree a Little}

The participants in all the groups felt that the response option "Agree a little" would be equivalent to between " 3 " and " 4 " on an eleven-point scale. They described this option as "below-average", and believed that it would be selected if the participants actually "disagreed".

\subsubsection{Somewhat Agree}

The response option "Somewhat agree" was perceived as the average or mid-point score; which meant either partial agreement or agreeing on certain occasions. Interestingly, in Cape Town the participants perceived this option as being the most dependent on context, and refers to both the amount of pleasant or unpleasant experiences with friends, but also the intensity of these experiences. In North-Western Romania the participants indicated that this option meant that they "Have friends but only a few", and the numerical equivalent for this option was identified as "5 - 6". While the majority of children in Catalonia perceived this response as a neutral $/$ mid-point position (numerical equivalent of between " 5 " and "7"), one participant assigned "8 to 9", and another "3" and "4", observing more diversity of opinions when children evaluated "Somewhat Agree". The narratives related were of aspects in life that "could be improved", and others stated that this meaning was difficult to express with a label.

\subsubsection{Agree}

The response option "Agree" was identified as a straightforward option to be selected if there was clear agreement with the statement. In Cape Town, some participants indicated that this option would be selected if "the children felt that they had enough friends" (quantity) and "had good relations with them" (quality). There were others who felt that they would select this option even if they had few friends, but had good relationships with them, and if friends were 'good' friends. In this sense the quality of the relationships was more important than quantity. The participants in both Cape Town and North-Western Romania agreed that an equivalent numerical value would be "7 -8 ". However, in Catalonia the 
equivalent score on an 11-point scale would be more extensive, from "6" to "9". One third of the children situated this response at the mid-point, which they repeated was "7" or " 8 ". Some participants within this category expressed that respondents might be "feeling quite, but not totally, satisfied".

\subsubsection{Strongly Agree}

The participants in all groups indicated that the response option "Strongly agree" meant that they were in unequivocal or "complete" agreement. They explained that this option meant that they had no doubts at all about choosing the response. They further indicated that the numerical equivalent would be between "9" and "10". Examples in the Catalonia groups indicated that it meant "being satisfied with your friends and what you want", "Requests for friendship are not turned down despite you don't need more", while in North-Western Romania the participants expressed that it meant "Having a bunch of friends (e.g., 10 friends), and being pleased with them".

\subsubsection{Don't Know}

For the option "don't know", the participants in all groups felt that this either meant that the question was not understood, or that they were unsure about how to answer the question. In Catalonia, the participants made sense of this as a 'catch-all' response, which included more meanings. For example, they expressed experiencing less guilt in selecting this response, demonstrated in the following statements: "You don't want to tell it, you are embarrassed". "I think that maybe children are afraid about someone seeing their answers, and they do not express their feelings".

\subsection{Analysis of the Meaning of some Concepts Used in the Questionnaire}

In addition to exploring children's understanding of the particular numerical and verbal scale response options across the three contexts, the particular meanings ascribed to the various concepts used in the question were examined, and is discussed in the section that follows (see Table 4).

\subsubsection{Satisfied}

In Cape Town the participants described the concept of "satisfied" as a 'feeling', which meant "feeling good or okay" (Table 4). They further described it as being accepting of a certain situation, but none of the participants felt that it was synonymous with "happiness". It is important to note that the participants in Cape Town and Catalonia also agreed that the word was hardly ever used by children or young people. In Catalonia they said: "We are not really using this word", "We use the word happy and contented, not satisfied".

In Catalonia, "Satisfied" was often assigned the meaning of being contented, happy, and feeling good; but also as an agreement ("You agreed"). The participants expressed this feeling saying; "You don't want to change, you are already fine", "You are happy and contented", and "You are comfortable, fine". A more complete definition was the following: "Being satisfied is for a reason, something that happened to you, for 
Table 4 Meanings of some concepts in the questionnaire

Category: meaning of concepts used in the questionnaire

Was this topic discussed in each group?

\begin{tabular}{|c|c|c|c|c|}
\hline \multicolumn{2}{|l|}{ Sub-categories: } & $\begin{array}{l}\text { South } \\
\text { Africa }\end{array}$ & Spain & Romania \\
\hline \multirow[t]{4}{*}{ Meaning of "satisfied" } & To feel good or okay & Yes & Yes & Yes \\
\hline & Happy, contented & & Yes & Yes \\
\hline & Acceptance; to agree & Yes & Yes & Yes \\
\hline & It's not a commonly used word by children & Yes & Yes & \\
\hline \multirow[t]{3}{*}{ Meaning of "happy" } & It is a feeling of "joy". Contented. Pleased. & Yes & Yes & Yes \\
\hline & $\begin{array}{l}\text { Words like: Fun, good, like, glad, pleasure, } \\
\text { meaningfully, laugh, rewards, etc. ... }\end{array}$ & & & Yes \\
\hline & It's a commonly used word by children & Yes & Yes & \\
\hline \multirow[t]{2}{*}{ Meaning of "school" } & It includes the building and school grounds. & Yes & Yes & \\
\hline & $\begin{array}{l}\text { Going to classes, participating in activities } \\
\text { and being with your friends. }\end{array}$ & Yes & & \\
\hline
\end{tabular}

instance maybe someone told you off and at the end he or she apologised, so you are satisfied about it. On the contrary, being contented is when you are happy about something that happened to you". In the groups conducted in North-Western Romania, they also used words like: "convenient", "you like", "happy", "contented", and "glad".

\subsubsection{Happy}

For the participants in Cape Town the word "happy" was also used to describe feelings and states of joy under circumstances when "things are going well and you are feeling well, about various things in your life". They explained that it could be used across various situations and in various aspects of life. At a basic level it meant to be "pleased" with aspects of life: "Happy is a feeling that you get when things are going good and when you are feeling pleased with your life". Both in Cape Town and Catalonia the word "happy" was considered a more commonly-used word.

In Catalonia the participants related being "happy" to people and things, to being contented "with what you have or what the other ones have!", "Or with yourself", "Or with your surroundings and with yourself". In North-Western Romania, meanings like: "When you laugh", "you feel good", "you have fun", "you do something meaningfully for you”, "you do something that reminds you”, "you 'eat' a rainbow and you get out of your skin", "you have good marks, you receive rewards", "when you like someone", and "a feeling you can't forget".

Regarding the difference between satisfied and happy, in Catalonia the participants mentioned that "being satisfied is like being satisfied with a thing. But for bigger things such as your life or your environment, you would use words such as happiness!" Moreover, in North-Western Romania the participants indicated that: "the happiness is more intensive than satisfaction". It was thus demonstrated that being happy seems to be a more complete and broad concept for children across the contexts. 


\subsubsection{School}

In Cape Town and Catalonia, the word school was understood in many different ways, but in Catalonia referred mainly to the physical aspect, such as the building or cleanliness, and timetable; and the building and school grounds in Cape Town. In the latter, the word "school" was understood also as "attending school" and participating in various schools' activities (attending classes, participating in sport). Importantly, it also meant engaging with and spending time with friends at school.

\subsection{Preferences of Question and Instrument Types}

Table 5 demonstrates the instrument preferences for SWB well-being measures with children across the three contexts.

Table 5 Instrument preferences

Category: Instrument preferences and how to investigate

Sub-categories:
Was this topic discussed in each group?

\begin{tabular}{|c|c|c|c|c|}
\hline \multicolumn{2}{|l|}{ Sub-categories: } & $\begin{array}{l}\text { South } \\
\text { Africa }\end{array}$ & Spain & Romania \\
\hline \multirow{3}{*}{$\begin{array}{l}\text { Preference for } \\
\text { categorical response }\end{array}$} & Easier to understand & Yes & Yes & \\
\hline & The selection of an option was clear & Yes & Yes & \\
\hline & Consistency between respondent and analyst & Yes & Yes & \\
\hline \multirow[t]{3}{*}{$\begin{array}{l}\text { Preference for numerical } \\
\text { response }\end{array}$} & $\begin{array}{l}\text { Children were familiar with this response format } \\
\text { and it was used in everyday life }\end{array}$ & Yes & Yes & \\
\hline & It offered a degree of preciseness & Yes & Yes & \\
\hline & Quicker, more convenient, easier to answer & & Yes & \\
\hline \multirow[t]{2}{*}{ Paper or online? } & Paper & Yes & & Yes \\
\hline & Online & & Yes & Yes \\
\hline \multirow{3}{*}{$\begin{array}{l}\text { How to investigate } \\
\text { well-being }\end{array}$} & Using a questionnaire & Yes & Yes & Yes \\
\hline & Asking children directly & Yes & Yes & Yes \\
\hline & $\begin{array}{l}\text { Asking children to make drawings about their } \\
\text { lives; other methods to tell their stories }\end{array}$ & Yes & Yes & Yes \\
\hline \multirow[t]{3}{*}{$\begin{array}{l}\text { Evaluating the } \\
\text { questionnaire }\end{array}$} & $\begin{array}{l}\text { Be unsure how to answer the questions. Some } \\
\text { questions can be understood in different ways }\end{array}$ & Yes & Yes & \\
\hline & $\begin{array}{l}\text { The initial explanations of how to answer the } \\
\text { different format questions were useful }\end{array}$ & Yes & & \\
\hline & $\begin{array}{l}\text { The format was very 'dull' and lacked colour. It } \\
\text { looked very complicated, unexciting and boring }\end{array}$ & Yes & Yes & \\
\hline \multirow[t]{2}{*}{$\begin{array}{l}\text { Proposals for } \\
\text { improvement }\end{array}$} & $\begin{array}{l}\text { Researchers should include some colour pictures } \\
\text { or graphics }\end{array}$ & Yes & & \\
\hline & $\begin{array}{l}\text { Create a space where children can construct a } \\
\text { drawing and write about things that contribute } \\
\text { towards their well-being }\end{array}$ & Yes & Yes & Yes \\
\hline
\end{tabular}




\subsubsection{Categorical or Numerical}

Table 5 shows the diversity of opinions on the preference for a categorical or numerical response format. This question sparked considerable debate especially in Cape Town and Catalonia amongst the participants, with no consensus reached. Some of the respondents preferred the numerical response format asserting that it was easy to understand and that it offered a degree of preciseness. They added that it was a typical method for rating various options, and that children were familiar with assessing numerical scale response options. They indicated that for example "we use the $0-$ 10-point scale everyday ... all children understand it". In Catalonia, the participants similarly stated that the numerical format was quicker, more convenient and easier to answer, and expressed that "You could express yourself better using from 0 to 10"; "We understand it better", "Because you could be more exact", and "It is more comfortable and quicker".

Other participants preferred the verbal response scale, similarly claiming that it was easy to understand, and added that the selection of an option was clear and less ambiguous than the numerical scale. There is a sense that more interpretation was required for the numerical scale and that the verbal response scale had a higher degree of consistency in understanding between the respondent and the analyst. In Cape Town, one participant stated for example: "If I choose the agree option, then you can clearly understand the one I'm choosing. What I mean when I choose agree and what you think agree means is the same ... so there's no confusion between the person that's answering and the person that's reading my answer". They further argued that there could be variability between respondents when using the numerical scale: "what I mean when I choose a 7, and what someone else means when they choose the same number is different ...".

Similar sentiments were expressed in Catalonia: "If you tick an option with numbers you are already saying this thing, but maybe you (the researchers) could believe that we do not agree with this thing because it is an 8"; "So, it is like seeing the cup half empty or halffull! We could believe that 8 is fine, but maybe you could believe that it is a low mark"; "The categorical response or tag has a meaning but the number could have another meaning, and who is reading the results could believe anything"; "With the numbers you have more options, but people could understand the wrong thing"; and "If you are feeling bad it's difficult to tick a number ... it's a feeling that it has no number, in my opinion”.

Other participants in Catalonia reported the advantages and drawbacks of both response types, in that numerical responses provided more variability, but could also create more confusion. It would appear that the numerical response format was more convenient for them, but they were aware that it could be more misleading when the meaning of their answers were interpreted, as we see in the following quotation: "There are advantages and disadvantages ... here you have less options ... but what you tick is specific".

\subsubsection{How to Investigate Well-Being}

In Cape Town, when asked about the best way to investigate children's well-being, they suggested a range of methods, most of which lean towards participatory research. 
An interesting point was made in relation to the diversity of the childhood experience in South Africa, where the participants believed that "you need different ways because children in South Africa are very different and live in different circumstances". Both in Cape Town and Catalonia there was agreement that the questionnaires containing questions that children could choose a certain option would be useful "With a survey" (Catalonia). Other recommendations were that children provide drawings depicting children's lives, and having group discussions (Cape Town) or interviews, as represented in the following example from Catalonia: "To understand better what we mean with every response, you could conduct a small interview at the end"; and in NorthWestern Romania the participants indicated that it would be useful in: "Asking them questions", "Having a chat", "Talking to them".

In Cape Town the participants also mentioned that researchers should come up with innovative ways to engage with children in order for them to be "able to tell their stories". Examples from Catalonia were: "Asking them how are they doing with their lives"; "Going to a school and talk to the child and kindly ask them how is his or her life"; and "Asking about the private life". The key message was that children need to be asked directly about their lives. Examples for North-Western Romania like: " $B y$ playing, as we do now", "by playing different games", "Choosing not many children to work with, giving them toys and gadgets", or even rewarding: "Giving them sweets".

The participants agreed that there were some questions that they were unsure how to answer. This related to the actual wording of the questions and not the response format. They felt that the initial explanations of how to answer the different type of scale questions were very useful. In Catalonia the participants noted that "Sometimes the questions are a little bit difficult to understand", "Maybe it is because we read them very quick and we do not understand them, and maybe we read them slowly and we do not understand them either".

It is interesting to highlight that participants from North-Western Romania suggested that questions should be added about free time and hobbies, more questions regarding the relationship with family, friends, teachers, questions related to pets, and finally questions related to career aspirations.

\subsubsection{Format of the Questionnaire}

In relation to the format of the questionnaire, participants across the different regions found the format of the actual questionnaire to be boring and unexciting. They suggested that colour graphics be added to improve the overall look of the questionnaire. Importantly, they also recommended that the questionnaire be designed in a way that was more interactive and engaging for the children. More specifically, they recommended that a section be added where children could construct a drawing with annotated narratives about what makes them happy or unhappy in their lives. The key message was that answering the questionnaire should be seen as an exciting activity and not burdensome or as an extension of school-work. By way of example, in Catalonia a participant stated that: "Maybe, as it has happened with numbers responses, you are not expressing properly what you want to say, and if you would write it down it would be better". Finally, proposals for improving understanding of the instrument included: "conducting a brief final interview" or "adding tags to explain what the numbers mean". 
With regard to responding online or on paper, a preference was shown for the online format in Catalonia and most children in the North-Western Romania saying that "Paper economy", "You can correct if you want by giving other answer". In Cape Town the participants also preferred the paper questionnaire, as well as in North-Western Romania: "By writing I feel like a person (an adult) who works in an office", "It is more official", and "It is more original".

\section{Discussion and Conclusion}

The overarching aim of the study was to explore how children from three different contexts perceive, understand, and make sense of SWB instruments. Within this process, the study aimed to explore children's understanding of, and decision-making process used when completing, measurement instruments on SWB, specifically as it relates to numerical versus verbal response formats. Further to that, the study aimed to determine children's preferences for either numerical or verbal response formats. Finally, the study aimed to understand how children make sense of and understand key concepts related to SWB.

The main finding of the study is the similarities in children's understanding of the response options across the three contexts. While this does not represent a claim for a 'universal understanding' of measurement scale response formats, it is suggesting that there are similar cognitive processes that children across the contexts apply when making sense of and deciding on which response option to endorse. This was typical for both the verbal and numerical response formats. For the verbal response options, while there were similarities in understandings for most of the response options across the three contexts, for the option 'somewhat agree' there were more gradations in understanding. It was made sense of as a mid-point, in Catalonia and Cape Town and an aspect that could be improved in North-Western Romania. While Lietz (2010) notes that complex vocabulary can increase the likelihood of participants selecting the 'don't know' option, leading to an inaccurate reflection of their perceptions, given the researcher-administered nature of the questionnaire particularly with younger children selecting this option is acceptable. As evidenced from the participants' understandings, this option was selected when they were 'not sure' of their response or a lack of understanding of the question, which is akin to empirical research with adults (Lietz 2010). For this reason, a key component of the questionnaire validation process is adaptation to the context in which it will be used, that includes appropriate translation to relevant languages, as well as the use of cognitive testing (interviewing) and pilot testing. The latter two thus enable and mitigate possible misunderstandings that may arise (see Casas et al. 2012; Savahl et al. 2019). This is in line with international best practice, such as the International Test Commission Guidelines (2016).

Importantly, the findings are suggesting that there are advanced cognitive processes and considerations that children use when considering items on SWB scales. The endorsement of a certain response option is thus not an indiscriminate process. Another key finding of the current study is that it provides a unique perspective on the process of how children make sense of the declarative statement, how they understand the response options, and which aspects of life they draw on for the final endorsement. In terms of questionnaire design, the study advances the use of cognitive interviewing with focus 
group interviews, using the 'hybrid model' technique that entails 'think-aloud approaches' and 'verbal response' (Ryan et al. 2012), as well as follow-up or stand-alone studies that further examine perceptions of scale granularity of the measures used with children. This can be undertaken before or after administration of the questionnaire.

The results are suggesting a high degree of concordance in relation to children's understandings of the categories on the verbal response format across the three concepts. This was especially evident for the agreement scale. Ultimately, this is an important finding as it enhances the opportunities for cross-cultural comparability. How children across the various contexts understand and perceive their respective different contexts are similarly promising for cross-cultural research. A similarly noteworthy finding was the reasonable level of consensus in relation to the key concepts of 'satisfaction' and 'happiness', with the latter ostensibly perceived of as being a more intense feeling, as well as being a more broad-based descriptive term. It is evident from all three contexts that children identified with and used the concept of 'happy' in their vocabulary, which they distinguished from satisfied. For children in this study, 'happy' had more positive connotations and more accurately embodied and reflected what they felt about multiple domains; such as the self, family, school, friends, and community that they live in. This finding could potentially have implications in terms of the measurement of life satisfaction, happiness, and SWB. Previously, these terms were used synonymously, with research demonstrating high levels of correlation coefficients suggesting that the concepts were indistinguishable (see Cummins 2014; Cummins et al. 2001).

Children's explanations of how they made sense of the numerical 0 to 10 -point scale provided a unique perspective of their decision-making process - it appears to align to the traditional four-step model of comprehension, retrieval, judgement, and estimation, and reporting (Tourangeau 2018). While this is not dissimilar to how adults would comprehend a declarative statement and endorse a response option, the meaning ascribed to the response options by children may differ to that of adults. There is a tendency to hold the position that children may be more affected by the 'life optimism bias', are constrained by under-developed cognitive capacities to meaningfully reflect on the items on the questionnaire, and may lack the developmental maturity to endorse a considered response option. However, research using SWB scales with a range of children between the ages of 8 to 12-years-old have consistently shown that children score between 70 to 80 on 100-point SWB scales (see Casas et al. 2011). These results similarly align to the theoretical assertion propagated by Cummins (2010) who states that SWB is maintained within pre-determined genetic set-points.

The current study provides some insight into the meaning ascribed to the response options on the numerical scale. It is interesting to note how the participants process the information; from making sense of the declarative statement and item content, aligning it to a numerical value on the predetermined scale, and then invoke a narrative explanation to the numerical value. In this instance, the sensitivity of the 0 to 10 -point scale is useful and it provides a level of precision that ultimately lends itself to a narrative interpretation. It is, however, clear that how the participants are making sense of the $0-10$ options is unique. For example, the results are suggesting that for many children (from Cape Town and Catalonia), the option " 7 " is perceived as the median point when interpreting items on a 0 to 10-point satisfaction scale. However, in North-Western Romania the option " 7 " is perceived to be higher than the mid-point or median score. 
Concerning the preferences for either the numerical or verbal-response formats the results were varied, with some children preferring the precision offered by the numerical format, while others suggested that the verbal response formats were less ambiguous. There did not seem to be any preference across the different contexts. It may be down to personal preferences - those preferring a numerical way of thinking versus those who are more verbally inclined. The current study is, to our knowledge, the only existing empirical study that explores scale granularity of SWB measures from the perspective of children. Given the proliferation of research on children's SWB over the past three decades (see Casas et al. 2012), the contribution of the study is significant. As data and information from large-scale surveys, such as the Children's Worlds Study (see www.isciweb.org), become available their capacity to contribute to public policy and services for children will, to a large extent, depend on the validity and reliability of interpretations derived from self-report measures (Ryan et al. 2012). The findings from the current study contributes to the field of 'cognitive aspects of survey methodology' with regard to child research and response processes. A related area of research is children's understanding of the item content in terms of the level of item abstraction, and children's cognitive capacity to understand the content and the meaning of the item. Recent research (see Tomyn et al. 2017) has identified issues around response bias, which they attribute to children's lack of cognitive capacity to understand abstract items on SWB measures. Findings from the current study allay this concern and provides an alternative explanation - it is likely that the response bias is an artefact of how children make sense of and process the response options, which is different to that of adults.

While the study includes children's voices from three disparate contexts, it is limited in its generalizability across different cohorts of children (e.g. across different age groups, gender socio-economic status, and geographical context). Further to that, the study only includes a focus on a limited number of measurement instruments. Future studies should endeavour to focus on a range of different contexts and cohorts of children and include different types of measurement scales and response options.

\section{References}

Adams, S., Savahl, S., \& Fattore, T. (2017). Children's representations of nature using photovoice and community mapping: Perspectives from South Africa. International Journal of Qualitative Studies on Health and Well-Being., 12. https://doi.org/10.1080/17482631.2017.1333900.

Ben-Arieh, A. (2000). Beyond welfare: Measuring and monitoring the state of children - New trends and domains. Social Indicators Research, 52(3), 235-257.

Ben-Arieh, A., Casas, F., Frønes, I., \& Korbin, J. (Eds.) (2014) Multifaceted concept of child well-being, In A. Ben-Arieh, F. Casas, I. Frønes, and J. Korbin (Eds.), Handbook of child well-being (pp. 1-27). Dordrecht: Springer.

Braun, V., \& Clarke, V. (2006). Using thematic analysis in psychology. Qualitative Research in Psychology, 3(2), 77-101. https://doi.org/10.1191/1478088706qp063oa.

Casas, F., Bălțătescu, S., Bertran, I., González, M., \& Hatos, A. (2013). School satisfaction among adolescents: Testing different indicators for its measurement and its relationship with overall life satisfaction and subjective well-being in Romania and Spain. Social Indicators Research, 111, 665-681. https://doi. org/10.1007/s1 1205-012-0025-9.

Casas, F., \& Bello, A. (Coord.), (2012). Calidad de vida y bienestar subjetivo en España. Qué afecta al bienestar de niños y niñas españoles de $1^{\circ}$ de ESO? Girona: Documenta Universitaria, UNICEF, España. 
Casas, F., Castella-Sarriera, J., Abs, D., Coenders, G., Alfaro, J., Saforcada, E., \& Tonon, G. (2011). Subjective indicators of personal well-being among adolescents. Performance and results for different scales in Latin-language speaking countries: A contribution to the international debate. Child Indicators Research, 5, 1-28. https://doi.org/10.1007/s12187-011-9119-1.

Casas, F., Coenders, G., González, M., Malo, S., Bertran, I. and Figuer, C. (2012). Testing the relationship between parent's and their own children subjective well-being. Journal of Happiness Studies, 13(6), 1031-1051. https://doi.org/10.1007/s10902-011-9305-3

Casas, F., Bello, A., González, M., \& Aligué, M. (2013). Children's subjective well-being measured using a composite index: What impacts Spanish first-year secondary education students' subjective well-being? Child Indicators Research, 6(3), 433-460. https://doi.org/10.1007/s12187-013-9182-x.

Coelho, P. S., \& Esteves, S. P. (2007). The choice between a five-point and a ten-point scale in the framework of customer satisfaction measurement. International Journal of Market Research, 49(3), 313-339.

Cook, C. F., Heath, R., Thompson, L., \& Thompson, B. (2001). Score reliability in web or internet-based surveys: Unnumbered graphic rating scales versus Likert-type scales. Educational and Psychological Measurement, 61, 697-706.

Corsaro, W. A (2008). Sociologia Copilăriei, ediția a II a. Cluj Napoca: International Book Access.

Cummins, R. A. (2010). Subjective wellbeing, homeostatically protected mood and depression: A synthesis. Journal of Happiness Studies, 11(1), 1-17. https://doi.org/10.1007/s10902-009-9167-0.

Cummins, R. A. (2014). Understanding the well-being of children and adolescents through homeostatic theory. In A. Ben-Arieh, F. Casas, I. Frones, \& J. E. Korbin (Eds.), Handbook of child well-being: Theories, methods and policies in global perspective (pp. 635-662). Dordrecht: Springer.

Cummins, R.A., Eckersley, R., Pallant, J., Misajon, R., \& Davern, M. (2001). Australian Unity wellbeing index: Survey 2, report 1.0. Australian Centre on quality of life, School of Psychology, Deakin University, Melbourne.

Fattore, T., Fegter, S., \& Hunner-Kreisel, C. (2018). Children's understandings of well-being in global and local contexts: Theoretical and methodological considerations for a multinational qualitative study. Child Indicators Research, 12(2), 385-407.

González-Carrasco, M., Casas, F., Viñas, F., Malo, S., \& Crous, G. (2019). The interplay between school and home location and its relationship with children's subjective well-being. Children's Geographies, 17, 676-690. https://doi.org/10.1080/14733285.2019.1635993.

International Test Commission. (2016). The ITC Guidelines for Translating and Adapting Tests (Second edition). [www.InTestCom.org].

James, A., \& Prout, A. (1990). Constructing and reconstructing childhood: Contemporary issues in the social construction of childhood. London: Falmer.

Jones, W. P., \& Loe, S. L. (2013). Optimal number of questionnaire response categories: More may not be better. SAGE Open, 3, 215824401348969. https://doi.org/10.1177/2158244013489691.

Krosnick, J. A. (1991). Response strategies for coping with the cognitive demands of attitude measurement in surveys. Applied Cognitive Psychology, 5(2), 213-236.

Lietz, P. (2010). Research into questionnaire design: A summary of the literature. International Journal of Market Research, 52(2), 249-272. https://doi.org/10.2501/S147078530920120X.

O' Muircheartaigh, C., Krosnick, J.A., \& Helic, A. (2000). Middle alternatives, acquiescence, and the quality of questionnaire data. Working papers 0103, Harris School of Public Policy Studies, University of Chicago.

O'Muircheartaigh, C., Gaskell, G., \& Wright, D. B. (1995). Weighing anchors: Verbal and numeric labels for response scales. Journal of Official Statistics, 11(3), 295-307.

Pearse, N. (2011). Deciding on the scale granularity of response categories of Likert-type scales: The case of a 21-point scale. The Electronic Journal of Business Research Methods, 9(2), 159-171.

Preston, C. C., \& Colman, A. M. (2000). Optimal number of response categories in rating scales: Reliability, validity, discriminating power, and respondent preferences. Acta Psychologica, 104(1), 1-15. https://doi. org/10.1016/S0001-6918(99)00050-5.

Rees, G., Andresen, S. \& Bradshaw, J. (Eds.) (2016). Children's views on their lives and well-being in 16 countries: A report on the Children's worlds survey of children aged eight years old, 2013-15. York, UK: Children's Worlds Project (ISCWeB).

Rees, G., \& Dinisman, T. (2015). Comparing children's experiences and evaluations of their lives in 11 different countries. Child Indicators Research, 8(1), 5-31.

Ryan, K., Gannon-Slater, N., \& Culbertson, M. J. (2012). Improving survey methods with cognitive interviews in small- and medium-scale evaluations. American Journal of Evaluation, 33(3), 414-430.

Saris, W. E., \& Gallhofer, I. (2007). Estimation of the effects of measurement characteristics on the quality of survey questions. Survey Research Methods, 1(1), 29-43. 
Saris, W. E., Satorra, A., \& Coenders, G. (2004). A new approach for evaluating quality of measurement instruments. Sociological Methodology, 34(1), 311-347.

Savahl, S., Adams, S., Florence, M., Casas, F., Mpilo, M., Isobell, D., \& Manuel, M. (2019). The relation between children's participation in daily activities, their engagement with family and friends, and subjective well-being. Child Indicators Research. https://doi.org/10.1007/s12187-019-09699-3.

Savahl, S., Malcolm, C., Slembrouk, S., Adams, S., Willenberg, I., \& September, R. (2015). Discourses on well-being. Child Indicators Research, 8(4), 747-766.

Schwarz, N., Knäuper, B., Hippler, H., Noelle-Neumann, E., \& Clark, L. (1991). Rating scales: Numeric values may change the meaning of scale labels. Public Opinion Quarterly, 55, 570-582.

Smithson, M. (2006). Scale construction from a decisional viewpoint. Minds \& Machines, 16, 339-364.

Tomyn, A. J., Fuller-Tyszkiewicz, M. D., Cummins, R. A., \& Norrish, J. M. (2017). The validity of subjective wellbeing measurement for children: Evidence using the personal wellbeing index-School children. Journal of Happiness Studies, 18, 1859-1875. https://doi.org/10.1007/s10902-016-9804-3.

Tourangeau, R. (2018). The survey response process from a cognitive viewpoint. Quality Assurance in Education, 26(2), 169-181.

Publisher's Note Springer Nature remains neutral with regard to jurisdictional claims in published maps and institutional affiliations.

\section{Affiliations}

\section{Carme Montserrat ${ }^{1} \cdot$ Shazly Savahl $^{2} \cdot$ Sabirah Adams $^{3}$ • Brîndușa Antonia Grigoraș $^{4}$ - Claudia Bacter ${ }^{5} \cdot$ Sergiu Bălțătescu ${ }^{5}$}

1 Faculty of Education and Psychology, University of Girona, Girona, Spain

2 Faculty of Community and Health Sciences, University of the Western Cape, Cape Town, South Africa

3 Centre for Higher Education Development, University of Cape Town, Cape Town, South Africa

4 Faculty of Sociology and Social Work, "Babeș-Bolyai” University Cluj-Napoca, Cluj-Napoca, Romania

5 Doctoral School of Sociology, University of Oradea, Oradea, Romania 